\title{
Effort to enhance paleoclimatic research in South Asia
}

\author{
Taniya J. Koswatta', X. Deng' ', A.V. Sijinkumar² and H.P. Borgaonkar ${ }^{3}$ \\ APN-PAGES Proposal Development Training Workshop, Paro, Bhutan, 14-16 December 2016
}

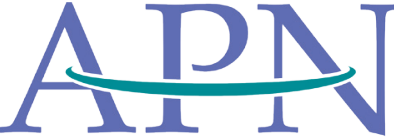

ASIA-PACIFIC NETWORK FOR GLOBAL CHANGE RESEARCH

\begin{abstract}
The Asia-Pacific Network for Global Change Research (APN) organized a three-day Proposal Development Training Workshop to enhance the capacity of young scientists in South Asia to develop competitive project proposals. The workshop provided an opportunity for young scientists to identify peer scientists working in the area of paleoclimate and develop regional research proposals. The workshop aimed to build transdisciplinary collaborations among climate scientists including paleoclimatology. Twenty young scientists from South Asia attended the training workshop and developed five proposals, two of which were developed to address paleoclimate issues in the region. Of the two proposals one focuses on the analysis of land-based tree-ring proxies, and the other focuses on lower-resolution proxies such as from marine sediment cores.
\end{abstract}

\section{Environmental changes in the}

Himalaya during the last millennium

Understanding past climate in the

Himalaya is especially important due to its prime role in maintaining and controlling the monsoon system over the Asian continent and serving as an orographic barrier to the cold winds blowing from the north into the subcontinent. In view of this, the group focused on reviewing the available meteorological data of the Himalayan regions. They pointed out that presently available data are not sufficient to provide a long-term trend analysis and realistic forecast of future trends. In this context, Himalayan trees offer an excellent dendroclimatic tool to reconstruct past climatic variations up to one thousand years. A few glacier and river run-off reconstructions were created, but these are limited to a specific location and do not capture climatic fluctuations in the heterogeneous terrain of the Himalaya. The group developed a regional proposal that aims to reconstruct regional, long term glacier extent and river run-off of the higher Himalayan region. This project aims to fill the data gap and provide an empirical relationship between climate-change glacier and river runoff. Findings of the study will help to produce evidence-based water resource and disaster management, among others.

\section{Asian monsoon system}

The second group focused on Asian monsoon variability and subsequent erosional history of the Himalayan and Burman ranges. The group designed a research proposal with the objective to document

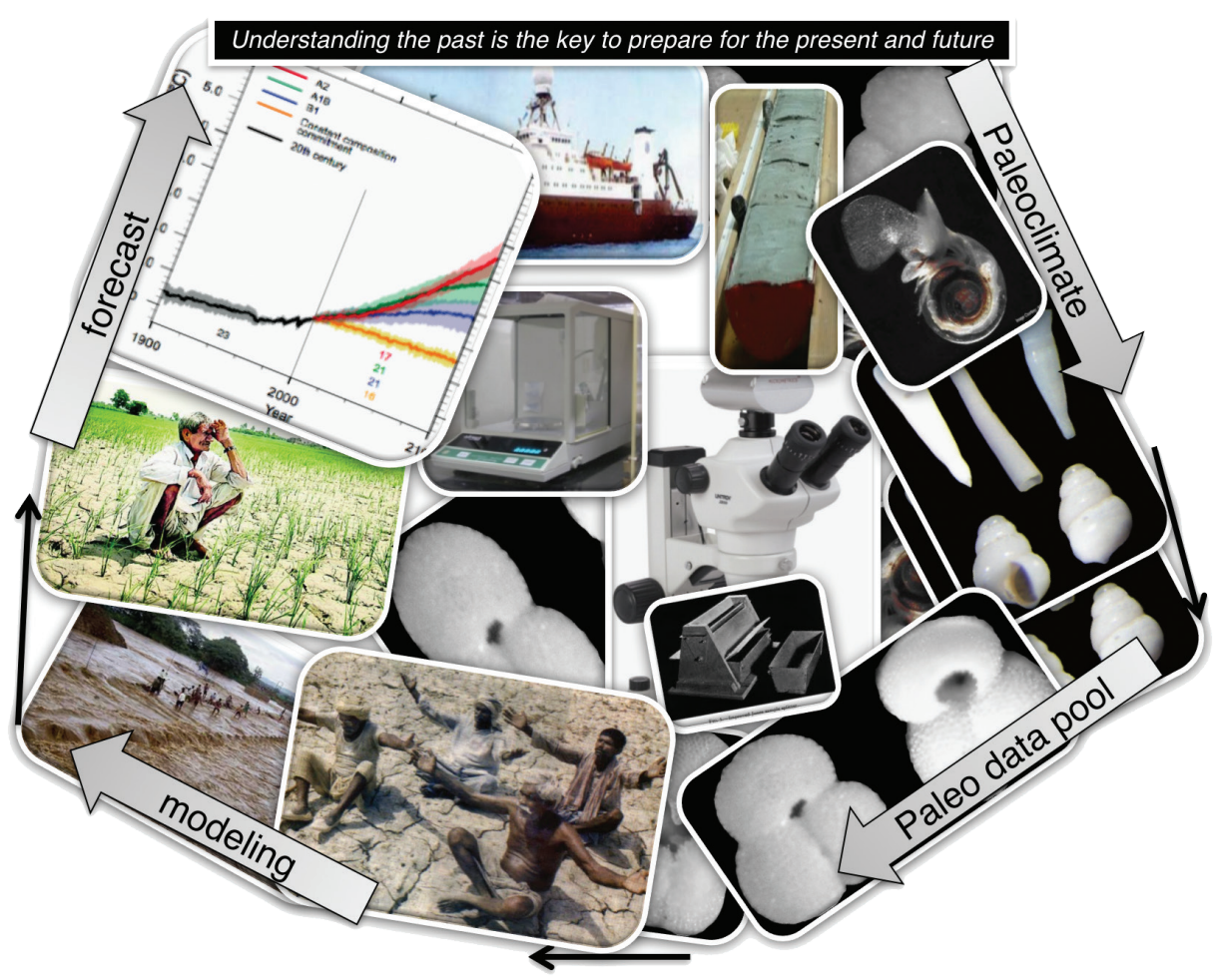

the paleoclimate changes (monsoon and sea-level changes) at centennial to millennial timescales by using quantitative and qualitative analyses of microfossils and sedimentary geochemistry. The Bay of Bengal was selected as the study area considering its continuous and high sedimentation rate (Akter et al. 2016). It is also a core convective area of the South Asian monsoon. The sediments of the Bay of Bengal are a good repository of climate-change information, especially Asian monsoon and sea-level fluctuations (Rashid et al. 2011). However, the available paleoclimate records from the region are either single-core based or of low resolution (Marzin et al. 2013; Gebregiorgis et al. 2016)

The group will also investigate the linkages between South Asian and East Asian monsoon systems. The project is planning to use multi-proxy micropaleontological (planktonic foraminifera, benthic foraminifera, pteropods, pollens and ostracodes) and geochemical analyses (stable isotopes, major, minor and rare earth elements) to decipher past climate and environmental conditions; the aim being to examine linkages between global climate and regional environmental change with relation to physical and biological systems. A conceptual framework of the project is indicated in Figure 1.

Both paleoclimate groups plan to submit the developed proposals to APN in 2017 for funding. Group members are seeking to expand the studies in the region by engaging more South Asia scientists and institutions.

\section{AFFILIATIONS}

'Asia Pacific Network of Global Change Research, Kobe, Japan

2Department of Geology, Central University of Kerala, India

Indian Institute of Tropical Meteorology, Pune, India CONTACT

Taniya Koswatta: tanijayani@gmail.com REFERENCES

Akter J et al. (2016) J Coastal Res 32: 1212-1226 Gebregiorgis D et al. (2016) Quat Sci rev 138: 6-15

Marzin C et al. (2013) Clim Past 9: 2135-2151

Rashid H et al. (2011) Terr Atmos Ocean Sci 22: 215-216 